\title{
Discrimination of roast and ground coffee aroma
}

\author{
Ian Denis Fisk ${ }^{1 *}$, Alec Kettle ${ }^{2}$, Sonja Hofmeister ${ }^{2}$, Amarjeet Virdie ${ }^{3}$ and Javier Silanes Kenny ${ }^{3}$
}

\begin{abstract}
Background: Four analytical approaches were used to evaluate the aroma profile at key stages in roast and ground coffee brew preparation (concentration within the roast and ground coffee and respective coffee brew; concentration in the headspace of the roast and ground coffee and respective brew). Each method was evaluated by the analysis of 15 diverse key aroma compounds that were predefined by odour port analysis.

Results: Different methods offered complimentary results for the discrimination of products; the concentration in the coffee brew was found to be the least discriminatory and concentration in the headspace above the roast and ground coffee was shown to be most discriminatory.

Conclusions: All approaches should be taken into consideration when classifying roast and ground coffee especially for alignment to sensory perception and consumer insight data as all offer markedly different discrimination abilities due to the variation in volatility, hydrophobicity, air-water partition coefficient and other physicochemical parameters of the key aroma compounds present.
\end{abstract}

Keywords: Coffee, Aroma, Flavour, Coffee brew, GC-MS, TOF-MS, Multivariate factor analysis

\section{Background}

The aroma of roast and ground (R\&G) coffee is critical to consumer liking and is perceived by consumers in one of many ways: the period directly after opening the pack is representative of the static partitioning of volatile chemicals between the R\&G coffee and the pack headspace; during early brewing the aroma is characteristic of the dynamic partitioning of volatile aroma compounds between the coffee, water, steam and air due to the infusion of water with the $R \& G$ coffee; the process of extraction involves the kinetic partitioning of volatile aroma compounds between the coffee and the water [1]; and finally the partitioning of volatile aroma compounds between the filtered aqueous brew, $R \& G$ fines, coffee oil and the headspace both above the cup and within the buccal and nasal cavity drives in-cup aroma [2,3]. All mechanisms are important to the overall perception of coffee aroma, and each contributes individually to key drivers of liking.

Differences in aroma between R\&G coffee originate from a number of sources: coffee beans may originate from different coffee plant cultivars (for example Arabica, Robusta) [4]; intrinsic bag to bag and seasonal variation may also

\footnotetext{
* Correspondence: ian.fisk@nottingham.ac.uk

${ }^{1}$ Division of Food Sciences, University of Nottingham, Sutton Bonington Campus, Sutton Bonington, Near Loughborough, Leicestershire LE12 5RD, UK Full list of author information is available at the end of the article
}

contribute to differences [5,6]; in addition, sourcing from different geographical locations [7], differences in processing (wet $\nu$ s. dry processing) and ageing before roasting are also significant contributors to the final aroma profile. Additionally, roasting time-temperature profile and the type of roaster will also play a role in differentiating different coffees [8,9]. Although there are a large number of variables, often the primary ones are defined as genotype (cultivar), phenotype (growing location, environment), primary processing (wet $v s$. dry) [10], secondary processing (roast intensity, roast thermal profile) [9] and postproduction storage (consumer handling) [9,11]. Additional variables may include alternative processing $[12,13]$ that modifies the precursors or the presence of defects or ineffective processing regimes [14].

Green beans are largely non-aromatic [15] (contain green-musty notes) but contain a large number of chemical precursors (sucrose, chlorogenic acids, proteins, carbohydrates) that contribute significantly to the aroma of $R \& G$ coffee. The relative concentration of chemical precursors varies between different coffees depending on their origin and treatment. During roasting a complex mixture of aroma compounds is formed through a number of different chemical reactions (Maillard reactions, Strecker degradation, caramelisation, oxidation) to produce a complex mix of aroma compounds.

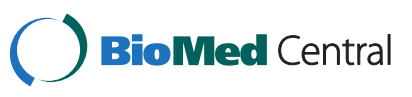


Over 850 aroma compounds have been associated with $R \& G$ coffee, these include hydrocarbons, alcohols, aldehydes, ketones, acids and anhydrides, esters, lactones, phenols, furans and pyrans, thiophenes, pyrroles, oxazoles, thiazoles, pyridines, pyrazines, and other nitrogenous and sulfurous compounds [16]. The ketones, acids, phenols, furans and pyrans, thiophenes, pyrroles, oxazoles, thiazoles pyridines and pyrazines are often found to be correlated to roasting intensity and methodology. Quantification of coffee volatiles is challenging due to the wide range of concentrations, high volatilities, wide range of physicochemical properties (for example polarity, pK, charge) and their potential to polymerise and bind to other coffee components.

Coffee volatile composition is typically analysed by gas chromatography followed by detection by mass spectrometer [17] or other specific detectors (flame ionization detectors [18], nitrogen-phosphorous detectors, photo-ionization detectors) which offer discriminative sensitivity to different classes of volatile compounds, extracted peak areas or spectra are then analysed by standard data analysis techniques or multivariate approaches [19-22].

The entire population of volatile aroma compounds found in R\&G coffee is not evaluated in this study, rather an evaluation of the different analytical approaches to understand and to quantify the relative presence of volatile aroma compounds during the preparation process (pack opening, water-coffee interaction and brew headspace) will be undertaken to evaluate the relative merits of each analytical approach and their relative discriminatory ability.

The aim of this study was to evaluate the discriminatory ability of a range of analytical approaches for measuring key aroma compounds of R\&G coffees and their respective brews.

\section{Results and discussion}

Table 1 lists the selected key aroma compound found in each sample of $R \& G$ coffee and their relative abundance is detailed in Table 2; principle component analysis and multivariate factor analysis are then used to illustrate differences in their concentration across the samples and methods, this is shown in Figures 1 and 2, respectively.

The most prevalent compounds in all samples were identified as 2,3 pentanedione, 2-methylbutanal, 3-methylbutanal and furfural, the concentration of most compounds in the brews exceeded the literature odour threshold, as shown in Table 1, although in some samples the concentration of maltol was found to be close to the threshold value, similar results have previously been reported by other authors $[22,26]$.

Of the four methods evaluated each has a different approach to profiling the volatile compliment of the coffee beverage, in addition, each has a different level of discriminatory ability. The diversity in discriminatory ability across the four analytical methods is due to different compounds having markedly different hydrophobicities, air-water partition coefficients and extraction efficiencies, leading to different aroma profiles and different drivers of product discrimination at different stages at preparation.

When the R\&G coffee is brewed, each compound will partition into the water phase to a different extent, for example high Log $\mathrm{P}$ compounds will be retained in the oil within the coffee whereas low log P compounds will partition out [27], in addition to log $\mathrm{P}$ there are a large number of other compounding physicochemical properties that will dictate the final concentration in the brew.

As the key liking step for coffee is traditionally defined as the consumption step, a principle component map is illustrated in Figure 1 showing the samples distributed by concentration within the brew (LLE). Principle component analysis on the brew concentration dataset identified two principle components for the 15 key aroma compounds (Figure 1). The first principle component (F1) accounted for $55 \%$ of the variance in the dataset and showed a high positive correlation to 2-acetylpyrazine, 2-acetylpyridine, furfurylmethylsulphide, trimethylpyrazine and phenylacetaldehyde. The second principle component (F2) accounted for $27 \%$ of the variance and showed a strong positive correlation with furfural, 2,3pentanedione, 3-methylbutanoic acid and a negative correlation with guaiacol (Figure 1).

The four methods were compared by multivariate factor analysis to compare their discriminatory ability. When looking across all the methods all products can be discriminated from each other, but in some cases individual methods do not effectively discriminate, indicating that if discrimination is required then an alternative analytical approach should be chosen based on the user quality factor or the physical parameter under investigation and the requirement of the scientific hypothesis being challenged. Kenya and Espresso show the greatest discrimination, whereas Datera and Costa occupy a similar multidimensional space as described by multivariate factor analysis. In general, $R \& G$ headspace was most discriminatory and brew concentration was shown to be the least discriminatory.

\section{Conclusion}

The four methods evaluated (brew concentration, R\&G concentration, brew headspace and R\&G headspace) all offer complimentary results for the discrimination of products, characterization ability of analyte, and relevance to consumer quality factors, all approaches therefore should be considered when classifying $R \& G$ coffees for alignment to sensory perception data and consumer liking data.

\section{Methods}

The concentration of selected key aroma compounds was measured by a range of approaches on five $R \& G$ coffees. 
Table 1 Key aroma compounds, chemical structure, predicted $\log \mathrm{P}$ and $\mathrm{K}$ a/w and literature odour threshold (above an aqueous solution)

\begin{tabular}{lllll}
\hline Compound & Structure & Log $\mathbf{P}$ & $\mathbf{K}_{\mathrm{a} / \mathrm{w}}$ & Odour threshold \\
\hline E, E-2, 4-Decadienal & 3.33 & 0.008994 & $0.07 \mathrm{ppb}[23]$ \\
$25152-84-5$ & & &
\end{tabular}

\begin{tabular}{llll}
\hline 2,3-Pentanedione \\
$600-14-6$
\end{tabular}

2-Ethyl-3,6-dimethylpyrazine
13360-65-1

\begin{tabular}{lllll}
\hline 2-Methylbutanal \\
$96-17-3$
\end{tabular}

\begin{tabular}{lllll}
\hline $\begin{array}{l}\text { 3-Methylbutanal } \\
590-86-3\end{array}$ & 0.0065 & 1.23 & $0.17 \mathrm{ppb}[23]$
\end{tabular}

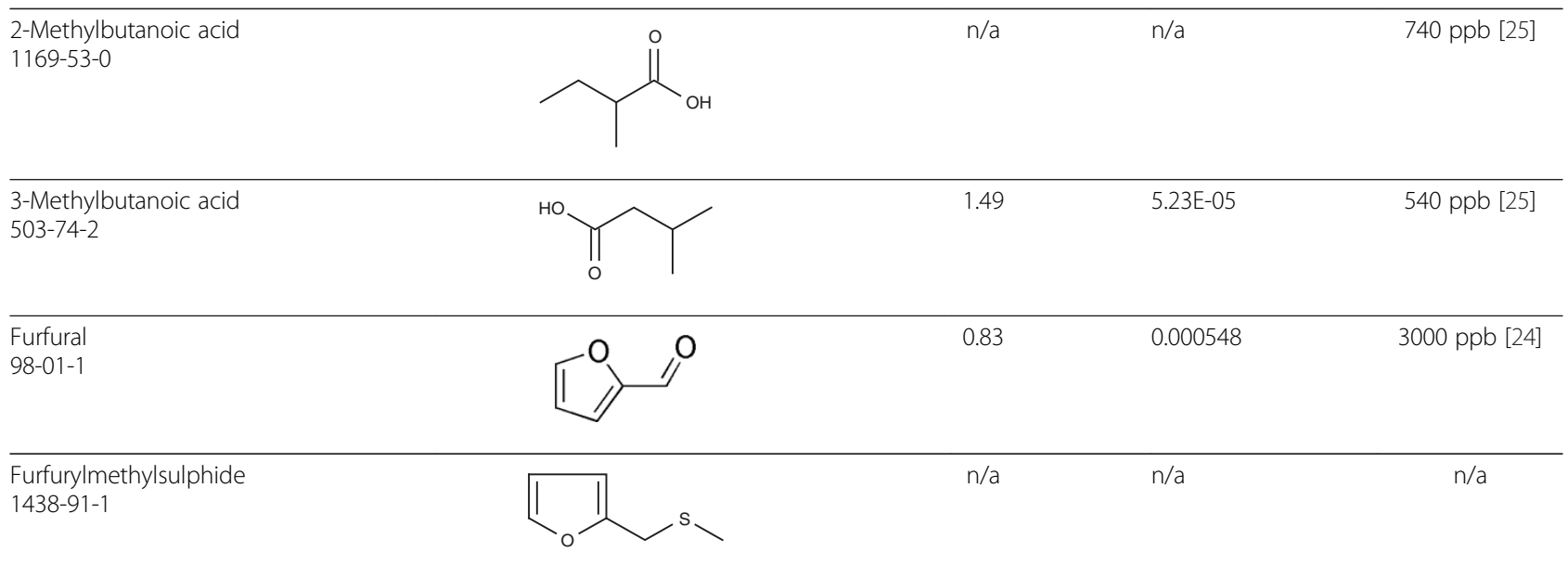


Table 1 Key aroma compounds, chemical structure, predicted $\log \mathrm{P}$ and $\mathrm{K}$ a/w and literature odour threshold (above an aqueous solution) (Continued)

\begin{tabular}{|c|c|c|c|}
\hline Guaiacol & 1.34 & $1.36 \mathrm{E}-06$ & 3 ppb [23] \\
\hline $\begin{array}{l}\text { Maltol } \\
118-71-8\end{array}$ & -0.19 & 0.000267 & 20 ppm [23] \\
\hline Phenylacetaldehyde & 1.54 & 0.000224 & 4 ppb [24] \\
\hline $122-78-1$ & & & \\
\hline Trimethylpyrazine & 1.58 & 0.00016 & 9 ppm [23] \\
\hline $14667-55-1$ & & & \\
\hline
\end{tabular}

The relative abundance of the key aroma compounds in the headspace above the R\&G coffee (R\&G SPME TOF) and above the coffee brew (Brew SPME TOF); and the concentration of select key aroma compounds in the R\&G (MASE GC-MS) and in the coffee brew (LLE GC-MS) was measured. Analytical approaches were chosen to represent key user liking criteria (for example aroma on opening the pack, aroma on brewing, aroma in the coffee beans and aroma in-cup on consumption) and all were shown to reliably measure key volatile compounds present in $R \& G$ coffee and coffee brew.

\section{Samples}

$R \& G$ arabica coffee was purchased from a commercial source in the United Kingdom; their origins are defined as Costa Rica, Java, Brazillian Daterra, Colombian and an espresso preparation (country of origin not disclosed on packaging). These were chosen as $R \& G$ coffee beans from the named locations have previously been shown to offer repeatable discrimination by aroma chemistry profiles [23,28]. Samples were frozen on day of purchase at $-80^{\circ} \mathrm{C}$ for no longer than 90 days.

\section{Key aroma compounds}

Aroma compounds of interest were previously identified by odour-port analysis as per Ullrich [29] (by the method of aroma extract dilution analysis) and are defined as key aroma compounds of R\&G coffee [23,30], compounds identified as having high seasonal variability (>10\% CV inter-batch variation) or rapid destabilization over storage (for example oxidation or polymerization) were excluded from this study, In addition, other compounds were not included in this paper for confidentiality reasons.

\section{Liquid-liquid sample preparation}

Volatiles were extracted (20 min) from $4 \mathrm{~g}$ of R\&G coffee brew using liquid-liquid extraction (LLE) with tertiary butyl methyl ether as the solvent $(2 \mathrm{~mL}$ ) above $2 \mathrm{~g}$ of anhydrous sodium sulphate, solvent was isolated by centrifugation (8000 RCF) and isolated solvent was analysed by direct injection GC-MS.

Membrane assisted solvent extraction sample preparation A total of $1.5 \mathrm{~g}$ of $\mathrm{R} \& \mathrm{G}$ coffee was dispersed in $10 \mathrm{~mL}$ of distilled water and capped in a membrane assisted solvent extraction (MASE) vial, Gerstel (Mülheim, Germany). One millilitre of TMBE was injected into the cap and the sample allowed to extract $(75 \mathrm{~min})$. Samples were centrifuged (8000 RCF) and solvent isolated by aspiration and analysed by direct injection GC-MS.

\section{Solid phase solvent extraction sample preparation}

Samples (5 g in $25 \mathrm{~mL}$ vial) were incubated for $15 \mathrm{~min}$ at $60^{\circ} \mathrm{C}$ and exposed to a $50 / 30 \mathrm{DVB} /$ Carboxen PDMS solid phase micro extraction (SPME) fiber for $15 \mathrm{~min}$ before direct thermal desorption within the GC-injector, with the inlet temperature set at $200^{\circ} \mathrm{C}$. 
Table 2 Key aroma compounds in six R\&G coffees as analysed by four analytical approaches (coffee brew and R\&G coffee headspace, coffee brew and R\&G coffee concentration, normalised by method to the Costa Rica preparation)

\begin{tabular}{|c|c|c|c|c|c|c|}
\hline & \multicolumn{6}{|c|}{ Coffee Brew LLE GC-MS } \\
\hline & Costa & Espresso & Java & Daterra & Kenya & Colombian \\
\hline E, E-2, 4-Decadienal & 100 & 48 & 57 & 64 & 75 & $\overline{53}$ \\
\hline 2,3-Pentanedione & 100 & 71 & 65 & 89 & 93 & 101 \\
\hline 2-Acetylpyrazine & 100 & 74 & 70 & 81 & 79 & 63 \\
\hline 2-Acetylpyridine & 100 & 77 & 76 & 82 & 88 & 69 \\
\hline 2-Ethyl-3,6-dimethylpyrazine & 100 & 94 & 86 & 89 & 81 & 61 \\
\hline 2-Methylbutanal & 100 & 91 & 70 & 70 & 101 & 69 \\
\hline 3-Methylbutanal & 100 & 87 & 65 & 70 & 97 & 64 \\
\hline 2-Methylbutanoic acid & 100 & 84 & 126 & 71 & 106 & 135 \\
\hline 3-Methylbutanoic acid & 100 & 96 & 91 & 78 & 115 & 169 \\
\hline Furfural & 100 & 68 & 79 & 74 & 95 & 125 \\
\hline Furfurylmethylsulphide & 100 & 77 & 55 & 67 & 79 & 52 \\
\hline Guaiacol & 100 & 167 & 116 & 87 & 114 & 79 \\
\hline Maltol & 100 & 1064 & 988 & 977 & 1042 & 859 \\
\hline Phenylacetaldehyde & 100 & 91 & 75 & 76 & 93 & 78 \\
\hline \multirow[t]{3}{*}{ Trimethylpyrazine } & 100 & 83 & 84 & 82 & 86 & 80 \\
\hline & \multicolumn{6}{|c|}{ Coffee Brew SPME TOF } \\
\hline & Costa & Espresso & Java & Daterra & Kenya & Colombian \\
\hline E, E-2, 4-Decadienal & 100 & 21 & 185 & 194 & 181 & 175 \\
\hline 2,3-Pentanedione & 100 & 76 & 58 & 90 & 91 & 73 \\
\hline 2-Acetylpyrazine & 100 & 53 & 35 & 66 & 5 & 49 \\
\hline 2-Acetylpyridine & 100 & 449 & 139 & 110 & 113 & 0 \\
\hline 2-Ethyl-3,6-dimethylpyrazine & 100 & 2 & 90 & 87 & 58 & 91 \\
\hline 2-Methylbutanal & 100 & 100 & 94 & 86 & 76 & 108 \\
\hline 3-Methylbutanal & 100 & 89 & 70 & 83 & 204 & 298 \\
\hline 2-Methylbutanoic acid & 100 & 234 & 224 & 130 & 424 & 160 \\
\hline 3-Methylbutanoic acid & 100 & 102 & 102 & 87 & 196 & 150 \\
\hline Furfural & 100 & 101 & 101 & 109 & 135 & 106 \\
\hline Furfurylmethylsulphide & 100 & 114 & 91 & 115 & 1580 & 78 \\
\hline Guaiacol & 100 & 193 & 123 & 94 & 82 & 118 \\
\hline Maltol & 100 & 84 & 122 & 79 & 88 & 131 \\
\hline Phenylacetaldehyde & 100 & 105 & 84 & 91 & 83 & 97 \\
\hline \multirow[t]{3}{*}{ Trimethylpyrazine } & 100 & 95 & 88 & 92 & 72 & 95 \\
\hline & \multicolumn{6}{|c|}{ Roast and Ground Coffee MASE GC-MS } \\
\hline & Costa & Espresso & Java & Daterra & Kenya & Colombian \\
\hline E, E-2, 4-Decadienal & 100 & 120 & 98 & 79 & 72 & 114 \\
\hline 2,3-Pentanedione & 100 & 78 & 74 & 109 & 112 & 112 \\
\hline 2-Acetylpyrazine & 100 & 93 & 87 & 101 & 65 & 97 \\
\hline 2-Acetylpyridine & 100 & 96 & 87 & 85 & 69 & 104 \\
\hline 2-Ethyl-3,6-dimethylpyrazine & 100 & 103 & 89 & 84 & 48 & 89 \\
\hline 2-Methylbutanal & 100 & 92 & 80 & 90 & 72 & 121 \\
\hline 3-Methylbutanal & 100 & 91 & 74 & 92 & 68 & 111 \\
\hline 2-Methylbutanoic acid & 100 & 99 & 176 & 53 & 135 & 117 \\
\hline 3-Methylbutanoic acid & 100 & 112 & 111 & 70 & 183 & 104 \\
\hline
\end{tabular}


Table $\mathbf{2}$ Key aroma compounds in six R\&G coffees as analysed by four analytical approaches (coffee brew and R\&G coffee headspace, coffee brew and R\&G coffee concentration, normalised by method to the Costa Rica preparation) (Continued)

\begin{tabular}{|c|c|c|c|c|c|c|}
\hline Furfural & 100 & 84 & 102 & 91 & 144 & 120 \\
\hline Furfurylmethylsulphide & 100 & 105 & 78 & 79 & 52 & 94 \\
\hline Guaiacol & 100 & 186 & 122 & 82 & 68 & 123 \\
\hline Maltol & 100 & 117 & 105 & 91 & 72 & 100 \\
\hline Phenylacetaldehyde & 100 & 103 & 80 & 72 & 68 & 105 \\
\hline \multirow[t]{3}{*}{ Trimethylpyrazine } & 100 & 100 & 96 & 96 & 67 & 103 \\
\hline & \multicolumn{6}{|c|}{ Roast and Ground Coffee SPME TOF } \\
\hline & Costa & Espresso & Java & Daterra & Kenya & Colombian \\
\hline E, E-2, 4-Decadienal & 100 & 141 & 134 & 82 & 161 & 150 \\
\hline 2,3-Pentanedione & 100 & 167 & 100 & 25 & 211 & 184 \\
\hline 2-Acetylpyrazine & 100 & 48 & 323 & 19 & 296 & 26 \\
\hline 2-Acetylpyridine & 100 & 398 & 149 & 107 & 197 & 169 \\
\hline 2-Ethyl-3,6-dimethylpyrazine & 100 & 92 & 87 & 109 & 376 & 134 \\
\hline 2-Methylbutanal & 100 & 149 & 81 & 33 & 88 & 142 \\
\hline 3-Methylbutanal & 100 & 147 & 76 & 28 & 86 & 138 \\
\hline 2-Methylbutanoic acid & 100 & 141 & 197 & 3 & 262 & 172 \\
\hline 3-Methylbutanoic acid & 100 & 152 & 136 & 10 & 284 & 165 \\
\hline Furfural & 100 & 140 & 152 & 48 & 256 & 178 \\
\hline Furfurylmethylsulphide & 100 & 89 & 61 & 48 & 51 & 66 \\
\hline Guaiacol & 100 & 252 & 170 & 49 & 121 & 161 \\
\hline Maltol & 100 & 104 & 107 & 1 & 121 & 116 \\
\hline Phenylacetaldehyde & 100 & 139 & 100 & 97 & 173 & 148 \\
\hline Trimethylpyrazine & 100 & 186 & 146 & 18 & 114 & 146 \\
\hline
\end{tabular}

\section{GC $\times$ GC TOF MS}

Chromatography was achieved with a Leco GC $\times \mathrm{GC}$ (modified Agilent 7890A, MI, USA) equipped with a split/ splitless injector containing a deactivated single tapered split liner and a liquid nitrogen, dual stage quad-jet thermal modulator (Leco, MI, USA). In the first dimension a Varian VF-5MS $15 \mathrm{~m} \times 0.25 \mathrm{~mm} \times 0.25 \mu \mathrm{m}$ column (Middelburg, the Netherlands) was used. In the second dimension an Agilent DB-1701 column $(1 \mathrm{~m} \times 0.10 \mathrm{~mm} \times 0.10 \mu \mathrm{m}$, Santa Clara, CA, USA) was used. A 20:1 split flow was used resulting in a total flow of $21 \mathrm{~mL} / \mathrm{min}$ set to constant flow. The inlet temperature was set to $200^{\circ} \mathrm{C}$ and the transfer line temperature set to $250^{\circ} \mathrm{C}$. Oven programming was set to an initial target temperature of $40^{\circ} \mathrm{C}$ for $30 \mathrm{~s}$ then increased at a rate of $10^{\circ} \mathrm{C} / \mathrm{min}$ to a target temperature of $260^{\circ} \mathrm{C}$. The secondary oven was set to an initial temperature of $50^{\circ} \mathrm{C}$ for $30 \mathrm{~s}$ then increased at a rate of $10^{\circ} \mathrm{C} / \mathrm{min}$ to a target temperature of $270^{\circ} \mathrm{C}$.

A dual stage quad-jet thermal modulator was used. The compounds reached the modulator and were trapped for $0.6 \mathrm{~s}$ then re-injected at a $30^{\circ} \mathrm{C}$ offset relative to the secondary oven. This temperature was held for $0.9 \mathrm{~s}$ with a total modulation time of $3 \mathrm{~s}$.

Detection was by mass spectrometer (LECO Pegasus ${ }^{\circledR}$ 4D Time-of-Flight mass spectrometer, MI, USA): detection range 35-600 amu, acquisition rate $200 \mathrm{spectra} / \mathrm{s}$, voltage $1550 \mathrm{~V}$ and a filament bias voltage of $-70 \mathrm{~V}$. The ion source was set to $200^{\circ} \mathrm{C}$ and the mass defect mode was set to manual.

\section{Direct injection GC-MS}

An Agilent 6890 gas chromatograph coupled with an Agilent 5975 mass spectrometer, equipped with Gerstel automated robot and a mid-polar Varian Factor Four ${ }^{\mathrm{rm}}$ (VF-1701 ms) column was used for the GC-MS analysis. Inlet temperature of the GC was set at $270^{\circ} \mathrm{C}$ and helium was the carrier gas with a column flow rate of $1.0 \mathrm{~mL} / \mathrm{min}$ in splitless mode. The oven parameters used were: $40^{\circ} \mathrm{C}$ with no hold, rising to $270^{\circ} \mathrm{C}$ at a rate of $30^{\circ} \mathrm{C} / \mathrm{min}$, holding for $1.33 \mathrm{~min}$. The injector temperature was constant at $280^{\circ} \mathrm{C}$ with an injection volume of $1 \mu \mathrm{l}$. The mass spectrometer operated in the electron ionization mode with an ion source temperature 


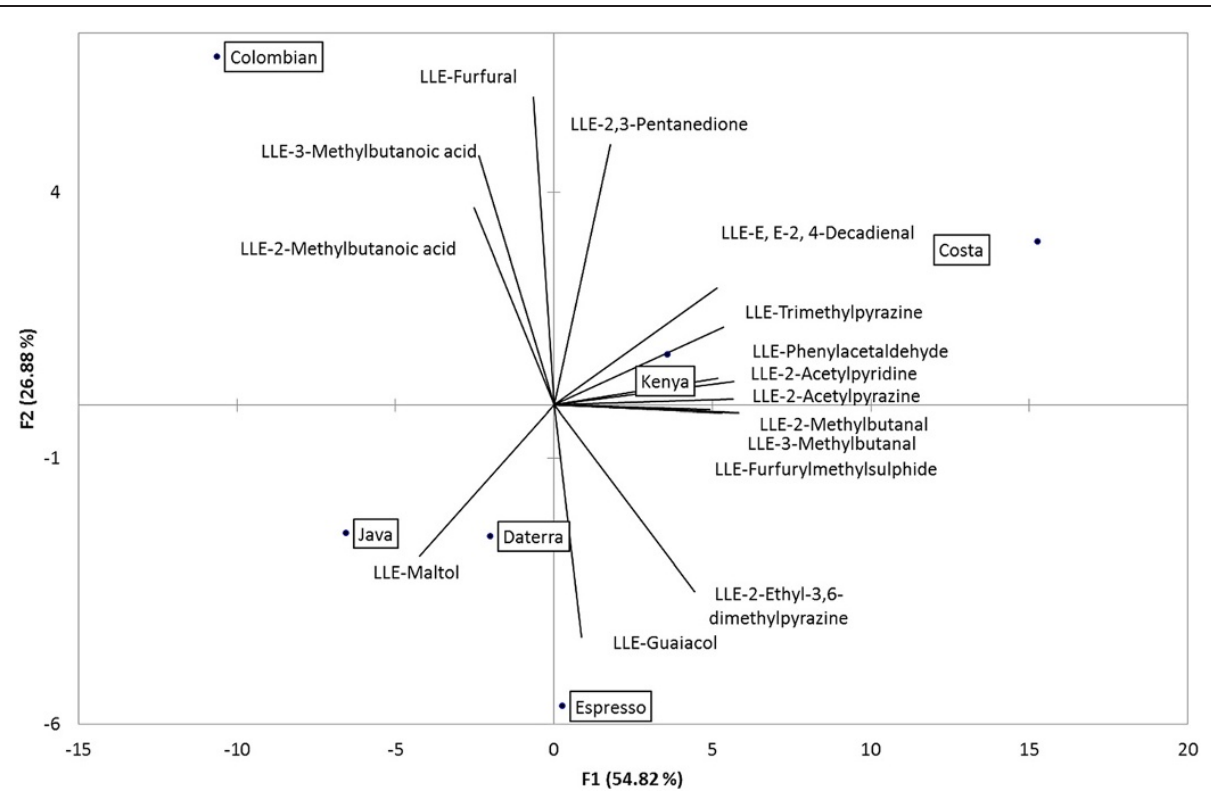

Figure 1 Principle component analysis of the aroma compliment of four R\&G coffees analyzed by brew concentration GC-MS.

of $230^{\circ} \mathrm{C}$ and a quad temperature of $150^{\circ} \mathrm{C}$. The full-mass range mode was used for the analysis of the standards with a mass range of $\mathrm{m} / \mathrm{z}$ 40-200 amu run in SIM/SCAN mode.

\section{Calibration}

Key aroma compounds of interest were identified using mass spectra, retention time and authentic standards. Concentrations were calculated against internal standards (1-pentanol, 4-heptanone) added prior to extraction, response factors were calculated for differential MS response and differential partition coefficients for each compound.

Calibration curves were generated in triplicate at five concentration points with authentic standards of all key aroma compounds, the concentrations varied depending

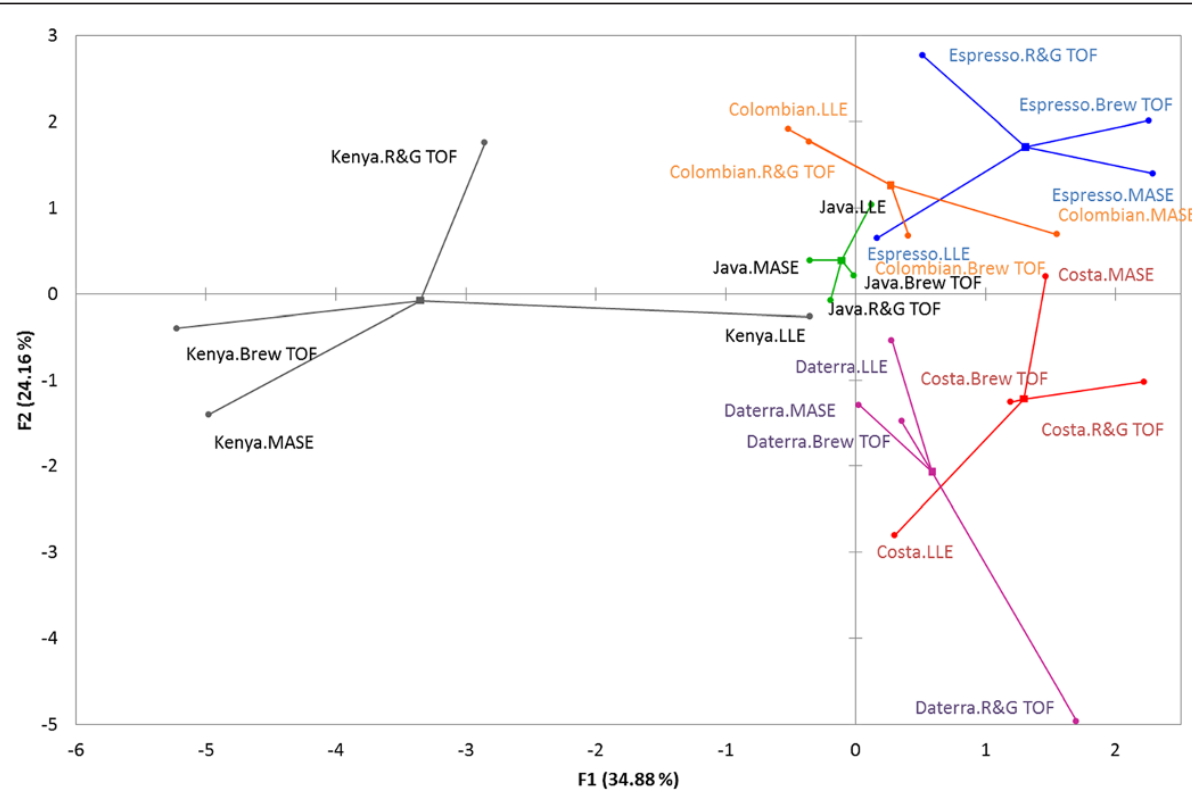

Figure 2 Multivariate factor analysis of four analytical approaches (brew headspace, R\&G headspace, brew concentration and R\&G concentration) for the volatile aroma compliment of six R\&G coffees. 
on analytical approach but in all cases the upper calibration point exceeded the maximum analysis concentration by two-fold. In all cases analytical reproducibility across multiple samples from a single production batch was $<10 \% \mathrm{CV}$.

The absolute $\mathrm{mV}$ response for each internal standard was tracked for each method and any deviation from normal distribution, trends towards abnormality or unexpected results resulted in machine clean down and recalibration.

\section{Moisture content}

Samples (2 g) were tested for moisture content as per Fisk et al. [31] to ensure that any significant deviation between origins would not impact the evaluation; there was no significant difference between the batches, $P<0.05$ by ANOVA.

\section{Statistical approach}

Triplicate samples were prepared from within a single production code of each sample set, samples were then analysed in duplicate by each method. Absolute concentration data was then evaluated for its discriminatory ability using principle component analysis and multivariate factor analysis, XLSTAT 2011 (Addinsoft, Anglesey, Wales), for data illustration the results are normalized to the Costa Rica preparation for each analytical approach.

Partition coefficients were calculated by EPI suite (US Environment Protection Agency, New York, NY, USA).

\section{Competing interests}

The authors declare that they have no competing interests.

\section{Authors' contribution}

IF and JSK conceived of the study, AV completed brew and R\&G analysis, SH completed headspace analysis, and AK participated in the manuscript creation. All authors read and approved the final manuscript.

\section{Acknowledgments}

IF, JSK, and AV are funded by Kraft Foods R\&D UK LTD. SH and AK are funded by Leco Corporation LTD.

\section{Author details}

${ }^{1}$ Division of Food Sciences, University of Nottingham, Sutton Bonington Campus, Sutton Bonington, Near Loughborough, Leicestershire LE12 5RD, UK. ' Leco Life Science and Chemical Analysis Centre, Monchengladbach, Germany. ${ }^{3}$ Kraft Foods R\&D UK Ltd, Ruscote Avenue, Banbury, Oxon OX16 2QU, UK.

Received: 22 December 2011 Accepted: 19 March 2012 Published: 1 August 2012

\section{References}

1. Fisk ID, Massey AT: Composition for preparing a beverage or food product comprising a plurality of insoluble material bodies. WO2011153064 20110526.

2. Steinhart H, Denker M, Parat-Wilhelms M, Drichelt G, Paucke J, Luger A, Borcherding K, Hoffmann W: Investigation of the retronasal flavour release during the consumption of coffee with additions of milk constituents by 'oral breath sampling'. Food Chem 2006, 98:201-208.
3. Yeretzian C, Pollien $\mathrm{P}$, Jordan A, Lindinger W: Liquid-air partitioning of volatile compounds in coffee: dynamic measurements using protontransfer-reaction mass spectrometry. Int J Mass Spectrom 2003, 228:69-80.

4. Semmelroch P, Grosch W: Studies on character impact odorants of coffee brews. J Agric Food Chem 1996, 44:537-543.

5. Mancha Agresti PDC, Franca AS, Oliveira LS, Augusti R: Discrimination between defective and non-defective Brazilian coffee beans by their volatile profile. Food Chem 2008, 106:787-796.

6. Da Silva EA, Mazzafera P, Brunini O, Sakai E, Arruda FB, Mattoso LHC, Carvalho CRL, Pires RCM: The influence of water management and environmental conditions on the chemical composition and beverage quality of coffee beans. Braz J Plant Phys 2005, 17:229-238.

7. Pawliszyn J, Risticevic S, Carasek E: Headspace solid-phase microextraction-gas chromatographic-time-of-flight mass spectrometric methodology for geographical origin verification of coffee. Anal Chim Acta 2008, 617:72-84.

8. Franca AS, Oliveira LS, Oliveira RCS, Agresti PCM, Augusti R: A preliminary evaluation of the effect of processing temperature on coffee roasting degree assessment. J Food Eng 2009, 92:345-352.

9. Bhumiratana N, Adhikari K, Chambers IV E: Evolution of sensory aroma attributes from coffee beans to brewed coffee. LWT Food Sci Technol 2011, 44:2185-2192

10. Gonzalez-Rios O, Suarez-Quiroz ML, Boulanger R, Barel M, Guyot B, Guiraud J-P, Schorr-Galindo S: Impact of "ecological" post-harvest processing on coffee aroma: II. Roasted coffee. J Food Compos Anal 2007, 20:297-307.

11. Bröhan M, Huybrighs T, Wouters C, Van der Bruggen B: Influence of storage conditions on aroma compounds in coffee pads using static headspace GC-MS. Food Chem 2009, 116:480-483.

12. Fisk ID, Gkatzionis K, Lad M, Dodd CER, Gray DA: Gamma-irradiation as a method of microbiological control, and its impact on the oxidative labile lipid component of Cannabis sativa and Helianthus annus. Eur Food Res Technol 2009, 228:613-621.

13. Budryn G, Nebesny E, Kula J, Majda T, Krysiak W: HS-SPME/GC/MS profiles of convectively and microwave roasted Ivory Coast Robusta coffee brews. Czech J Food Sci 2011, 29:151-160.

14. Cantergiani E, Brevard H, Krebs Y, Feria-Morales A, Amado R, Yeretzian C: Characterisation of the aroma of green Mexican coffee and identification of mouldy/earthy defect. Eur Food Res Technol 2001, 212:648-657.

15. Holscher W, Steinhart H: Aroma compounds in green coffee. In Developments in Food Science. Volume 37. Edited by George C. London: Elsevier; 1995:785-803.

16. Grosch W: Coffee: Recent developments. In Chemistry III: Volatile Compounds. Edited by Clarke RJ, Vitzthum OZ. Oxford: Blackwell Science; 2001:68-89.

17. Yeretzian C, Jordan A, Lindinger W: Analysing the headspace of coffee by proton-transfer-reaction mass-spectrometry. Int J Mass Spectrom 2003, 223-224:115-139.

18. Costa Freitas AM, Mosca Al: Coffee geographic origin-an aid to coffee differentiation. Food Res Int 1999, 32:565-573.

19. Fisk ID, Virdie A, Kenny J, Ullrich F: Soluble coffee classification through rapid scanning methodologies. In ASIC 2010; Bali. Bussigny: Association for Science and Information on Coffee; 2010.

20. Risticevic S, Carasek E, Pawliszyn J: Headspace solid-phase microextraction-gas chromatographic-time-of-flight mass spectrometric methodology for geographical origin verification of coffee. Anal Chim Acta 2008, 617:72-84.

21. Zambonin CG, Balest L, De Benedetto GE, Palmisano F: Solid-phase microextraction-gas chromatography mass spectrometry and multivariate analysis for the characterization of roasted coffees. Talanta 2005, 66:261-265.

22. Korhoňová M, Hron K, Klimčíková D, Müller L, Bednáŕ P, Barták P: Coffee aroma: Statistical analysis of compositional data. Talanta 2009, 80:710-715.

23. Flament I: Coffee Flavour Chemistry. Chichester: John Wiley and Sons LTD; 2002.

24. Buttery RG, Ling LC: Volatile flavor components of corn tortillas and related products. J Agric Food Chem 1995, 43:1878-1882.

25. Schieberle $P$, Hofmann T: Evaluation of the character impact odorants in fresh strawberry juice by quantitative measurements and sensory studies on model mixtures. J Agric Food Chem 1997, 45:227-232.

26. Semmelroch P, Grosch W: Analysis of roasted coffee powders and brews by gas chromatography-olfactometry of headspace samples. LWT Food Sci Technol 1995, 28:310-313. 
27. Mayer F, Czerny M, Grosch W: Sensory study of the character impact aroma compounds of a coffee beverage. Eur Food Res Technol 2000, 211:272-276.

28. Wang $N, F u Y$, Lin L: Feasibility study on chemometric discrimination of roasted arabica coffees by solvent extraction and fourier transform infrared spectroscopy. J Agric Food Chem 2011, 59:3220-3226.

29. Ullrich $F$, Grosch W: Identification of the most intense volatile flavour compounds formed during autoxidation of linoleic acid. $Z$ Lebensm Forschung A 1987, 184:277-282.

30. Fisk ID: Roast and ground coffee descrimination by aroma profiling. In 2nd European GCXGC symposium. Regensburg: Leco; 2011.

31. Fisk ID, Linforth R, Taylor A, Gray D: Aroma encapsulation and aroma delivery by oil body suspensions derived from sunflower seeds (Helianthus annus). Eur Food Res Technol 2011, 232:905-910.

doi:10.1186/2044-7248-1-14

Cite this article as: Fisk et al:: Discrimination of roast and ground coffee aroma. Flavour 2012 1:14

\section{Submit your next manuscript to BioMed Central and take full advantage of:}

- Convenient online submission

- Thorough peer review

- No space constraints or color figure charges

- Immediate publication on acceptance

- Inclusion in PubMed, CAS, Scopus and Google Scholar

- Research which is freely available for redistribution 